\title{
Analysis on River Bed Changes in Weir Downstream by Real-Scale Experiment
}

\author{
Dongwoo Ko, Joongu Kang* \\ Korea Institute of Civil Engineering and Building Technology (KICT), Goyang-Si, Gyeonggi-Do, Korea \\ Email: *jgkang02@kict.re.kr
}

How to cite this paper: Ko, D. and Kang, J. (2018) Analysis on River Bed Changes in Weir Downstream by Real-Scale Experiment. Engineering, 10, 505-513. https://doi.org/10.4236/eng.2018.108036

Received: July 26, 2018

Accepted: August 5, 2018

Published: August 8, 2018

Copyright (c) 2018 by authors and Scientific Research Publishing Inc. This work is licensed under the Creative Commons Attribution International License (CC BY 4.0).

http://creativecommons.org/licenses/by/4.0/

\begin{abstract}
Flood damage has aggravated recently owing to artificial structures in high flow rare areas such as small rivers, which can lead to secondary damage. In this regard, studies are required to examine the conventional design criteria formulas to secure the stability of structures such as weirs and drop structures. Although studies on the stability of these structures have been conducted through small-scale experiments, few empirical studies have investigated the hydraulic phenomena occurring near actual artificial structures. In this study, we fabricated real-size models of weir and drop structure at the Andong River Experiment Center and investigated the flow patterns around the structures by applying the particle image velocimetry analysis technique with a flow tracker. We also measured the scour length in the waterspout section when the structures are overflowing, and compared it with the values calculated using the formula. Consequently, as the supply flow increases, the result is different from the value calculated using the formula given in the existing design standard, and it is judged to be inappropriate for a small stream area with high flow rate. Thus, it is necessary to consider the design factors such as energy gradient and the flow amount per unit width into weir and drop structure as well as the existing design factors in designing an apron section for a weir and drop structure.
\end{abstract}

\section{Keywords}

Weir, Drop Structure, Real-Scale Experiment, River Bed, Scour Characteristic

\section{Introduction}

It is crucial to evaluate the stability of the design section in a weir and drop structure design for determining the stability. The stability evaluation should be precisely performed for every item if possible, considering the conditions such as 
flow characteristics, channel form, and bed slope. If a design section is determined to be unstable as a result of the stability evaluation, a method should be devised to redesign or improve the section based on the results [1] [2].

The stability of weirs and drop structures is evaluated in South Korea in terms of overturning, activity, and settlement. Japan also specifies that the stability evaluation for the design of weirs and drop structures should be based on overturning, activity, and settlement. However, the current domestic River Design Standard provides only the regulations for the design segment and the shape in the design of weirs and drop structures, while specifying no criteria for external force and internal force calculation for each stability evaluation item. Therefore, the design depends on judgments based on past experiences of structure installation. Thus, it is difficult to determine how stable the currently installed weirs and drop structures are against floods.

Quantitative and qualitative analyses have been conducted on the scour protection length and scouring characteristics of the apron at a weir downstream part according to the change in river bed slopes through the conventional small weir model experiment [3]-[8]. However, to derive a feasible improvement plan of the design standard, which is the objective of our study, the model scale effect must be minimized. Furthermore, to verify the reliability of previous model test results, comparative verification is required through empirical experiments. Thus, this study investigated the specifications and bed slopes of typical weirs and drop structures in small rivers through the existing literature review and field survey to apply the data to experiments. This study further examined the scour characteristics of the apron section at the downstream part depending on the real-size model fabrication and the actual flow rate. This study ultimately aims to propose an improvement plan for the scour protection length at the downstream parts of weirs and drop structures through experiment-based research.

\section{Real-Scale Experiment}

\subsection{Experimental Setup}

To investigate the scour protection length of the apron according to the bed slope, real-scale experiments on weirs and drop structures were conducted. The real-size weirs and drop structures were fabricated by the research team on the steep slope channel at the Andong River Experiment Center (A1), and the experiment was conducted in the range $1.7 \mathrm{~m}^{3} / \mathrm{s}$ to $5.0 \mathrm{~m}^{3} / \mathrm{s}$ according to the flow rate criteria in Figure 1.

The slope of the experimental water channel was selected as the representative value $0.03(3 \%)$ within the range 0.01 to 0.05 , which is the most commonly used value in reference to the status survey on domestic small rivers, and considering the site conditions where the control of the water channel slope is not easy.

The cross-section of the water channel is trapezoidal, with a reservoir width of $3 \mathrm{~m}$, height of $2 \mathrm{~m}$, and revetment slope of 1:2, with a total width of $11 \mathrm{~m}$. The 


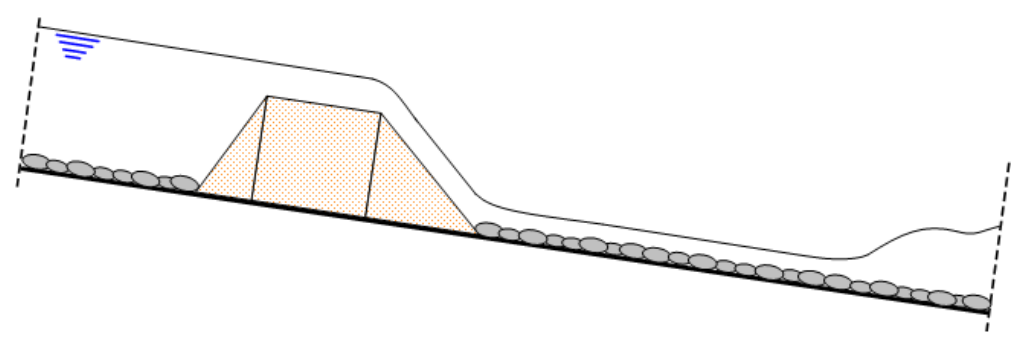

Figure 1. Cross-section of the weir model.

weir and drop structure models installed in the experimental water channel were designed as trapezoidal real-scale models, and the models were connected to both sides of the channel across the reservoir. The length was $3 \mathrm{~m}$ and the crest width was $1 \mathrm{~m}$ in Figure 2.

\subsection{Experimental Methods}

The real-scale experiment with a weir and drop structure was conducted to investigate the optimal apron length for the protection of downstream scour. Under the condition of $3 \%$ bed slope, the effect on downstream scour per flow rate was analyzed. The experimental flow rate was gradually increased from $1.7 \mathrm{~m}^{3} / \mathrm{s}$ to $5.0 \mathrm{~m}^{3} / \mathrm{s}$ to determine the upstream flow rate for five conditions, and the experiment was performed for the downstream boundary condition with outflow conditions. The experiment was conducted after $3 \mathrm{~h}$ of water flow to measure the downstream scour length for each flow rate. During the experiment, the flow rate distribution around the structure was measured through two methods using a flow tracker and particle image velocimetry (PIV). PIV is a whole-flow-field technique providing instantaneous velocity vector measurements in a cross-section of a flow. This technique being a non-intrusive one, allows the application of PIV in high speed flows, boundary layer studies of fluids. The technique is applicable to a range of liquid and gaseous flows. The fluid is seeded with particles which are generally assumed to faithfully follow the flow dynamics. It is the motion of these seeding particles from which the velocity information is calculated. It is done by taking two images shortly after one another and calculating the distance individual particles traveled within this time. The displacement field is determined from the motion of the seeding particles between the two images. The velocity field is obtained by dividing the displacement field by the known time separation. A total of 25 measurement points for the flow tracker were selected with five points for five measurement lines, respectively in Figure 3. For the riverbed material of the downstream part of the structure, boulder stones with a D50 of $0.35 \mathrm{~m}$ were installed to quantitatively examine the downstream scour of the weir.

\section{Result}

\subsection{Velocity Distribution near the Weir}

Figure 4 shows the flow rate distribution for three different flow rate conditions 

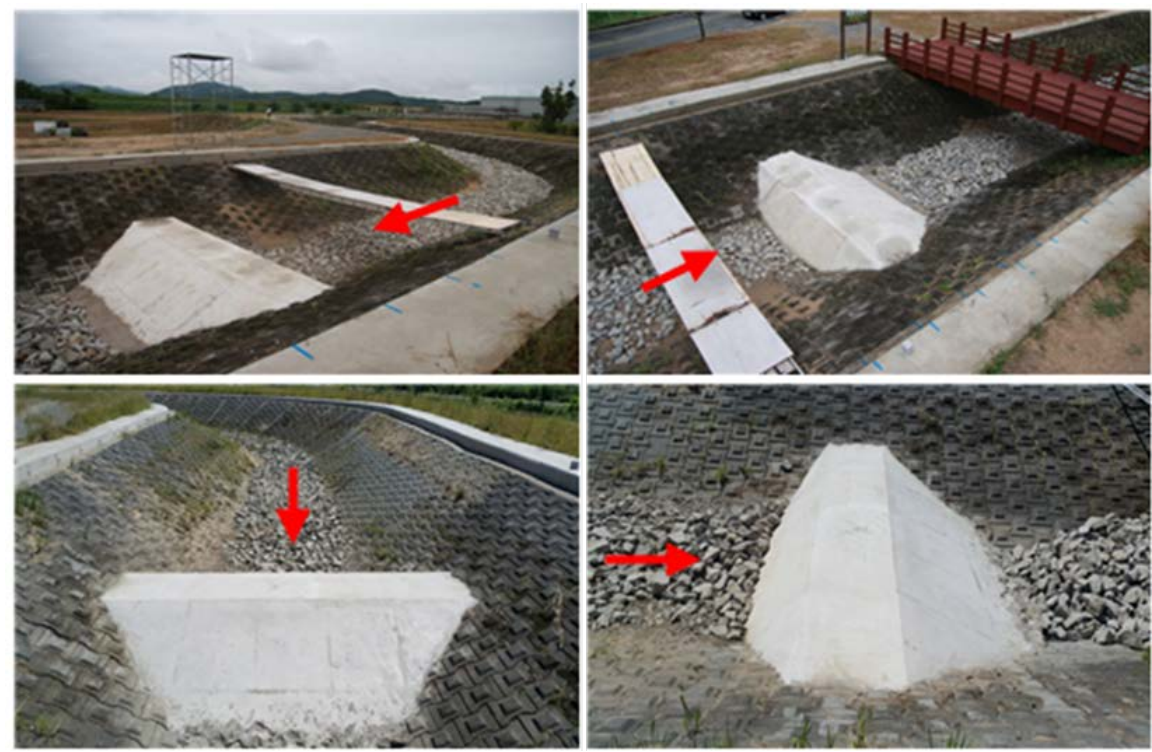

Figure 2. Weir model installed in the channel.

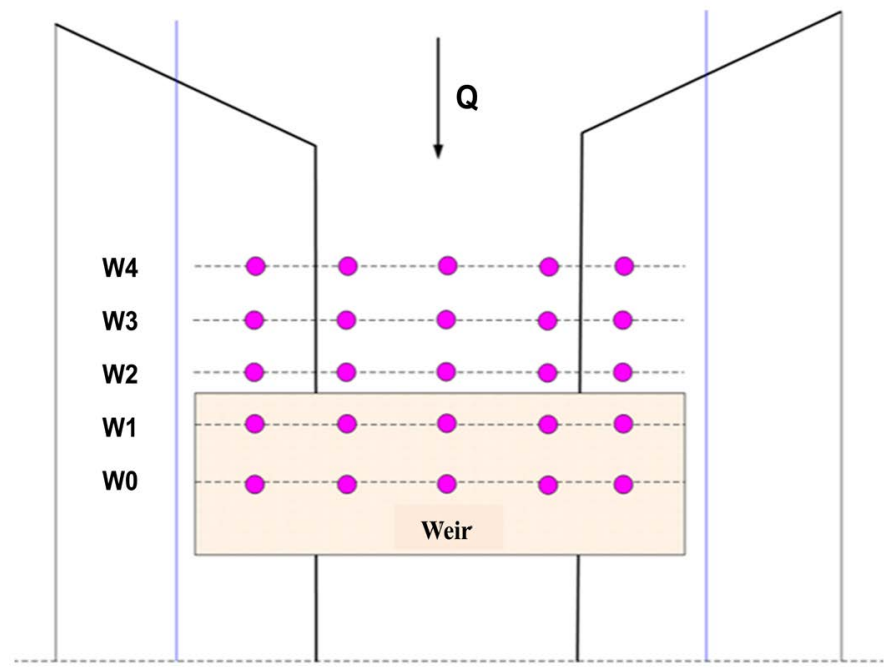

Figure 3. Measuring points for velocity.

$1.7 \mathrm{~m}^{3} / \mathrm{s}, 3.5 \mathrm{~m}^{3} / \mathrm{s}$, and $5.0 \mathrm{~m}^{3} / \mathrm{s}$ depending on weir installation using the flow tracker and PIV technique.

The flow at the upstream part of the weir shows that, after passing through the bight of the water channel, the flow concentrated to the left side of the channel at a maximum flow rate of $0.845 \mathrm{~m} / \mathrm{s}, 1.482 \mathrm{~m} / \mathrm{s}$, and $1.919 \mathrm{~m} / \mathrm{s}$ for the aforementioned experimental conditions, respectively. While the flow passed through the weir, the water depth decreased and the maximum flow rate increased to 1.946 $\mathrm{m} / \mathrm{s}, 2.445 \mathrm{~m} / \mathrm{s}$, and $2.655 \mathrm{~m} / \mathrm{s}$, respectively. At the downstream part, the flow passing through the weir became a supercritical flow, further changing into a subcritical flow after undergoing a hydraulic jump phenomenon at the downstream part of the weir. According to the results of the PIV analysis, the upstream flow shows the same flow pattern. 

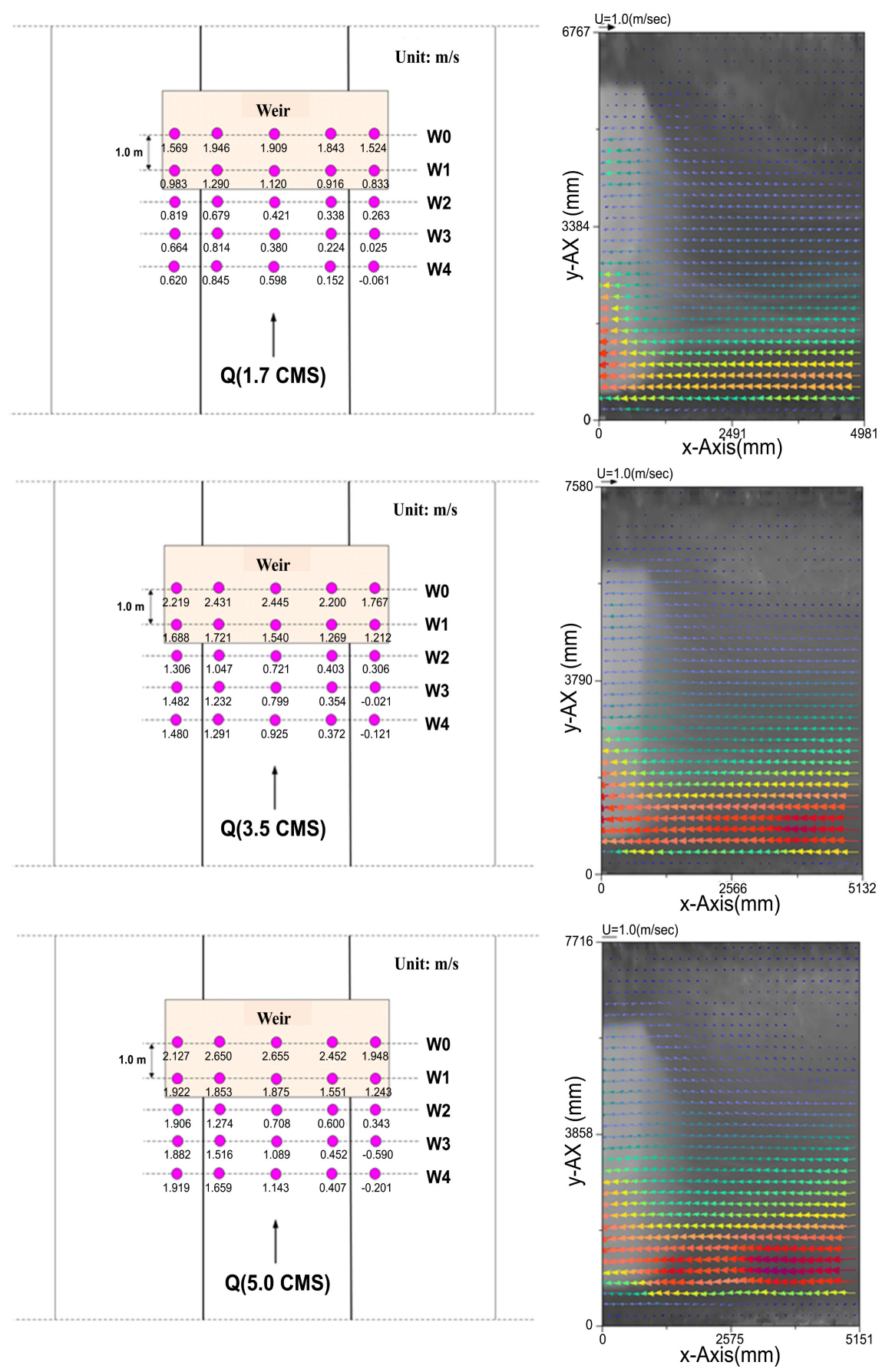

Figure 4. Velocity distribution near the weir.

\subsection{Velocity Distribution near the Drop Structure}

To compare the characteristics of the flow rate distribution of the weir and the drop structure, an experiment was conducted by modifying the weir model to the drop structure model conditions in Figure 5. As in the weir experiment, the flow rate distribution was measured for three flow conditions $1.7 \mathrm{~m}^{3} / \mathrm{s}, 3.5 \mathrm{~m} / 3$, and $5.0 \mathrm{~m}^{3} / \mathrm{s}$ by using the flow tracker and PIV technique in Figure 6 .

The flow at the upstream part of the drop structure showed that, after passing 

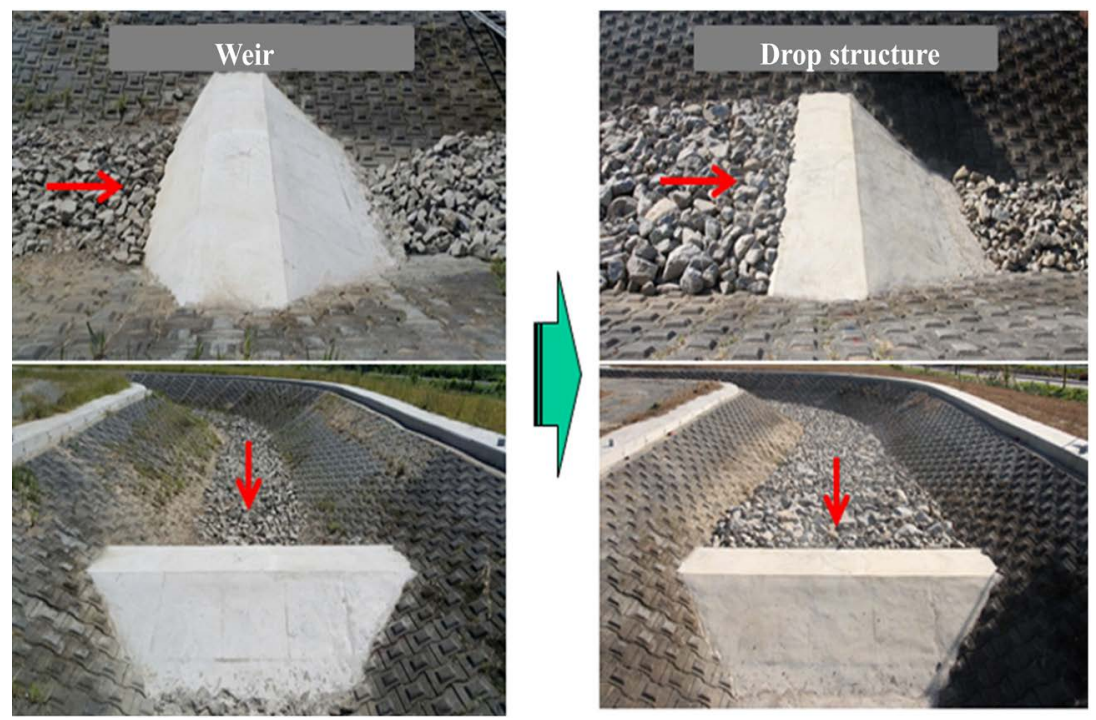

Figure 5. Model change from the weir to the drop structure.

through the bight of the water channel, the flow concentrated to the left side of the channel with the maximum flow rate of $1.457 \mathrm{~m} / \mathrm{s}, 1.647 \mathrm{~m} / \mathrm{s}$, and $2.326 \mathrm{~m} / \mathrm{s}$ for the aforementioned experimental conditions, respectively. However, owing to the lower water depth of the approach section when compared with the weir model, the overall flow rate tended to increase. While the flow passed through the drop structure, the water depth slightly decreased and the maximum flow rate increased to $1.845 \mathrm{~m} / \mathrm{s}, 2.246 \mathrm{~m} / \mathrm{s}$, and $2.809 \mathrm{~m} / \mathrm{s}$, respectively. At the downstream part, the flow shows the same pattern as the weir model experiment, and according to the results of the PIV analysis, the upstream flow shows the same flow pattern.

\subsection{Verification of Apron Scouring Protection Length along the Discharge}

According to the change in the flow amount, the flow rate significantly increased near the weir and the drop structure and during the passing of the flow through the structure. This is because the total energy of the water flow increased with the change in the flow amount.

This study compared both the formula given by the National Construction Research Institute, as in (1), and Bligh's formula, as in (2), presented in the River Design Criteria [9] with the scour length measured through the real-scale weir and drop structure experiments. Bligh's coefficient $(C)$ is differently defined according to the riverbed materials in Bligh's formula. Nevertheless, this study selected a range of $\mathrm{C}$ values for boulder stones and cobbles, which are common riverbed materials mainly distributed in the small rivers (boulder stone and cobble: $C=4-6)$.

$$
\begin{gathered}
L_{1}=4.05 H^{0.316} q^{0.514} D_{50}{ }^{-0.325} \\
L_{1}=0.6 C \sqrt{H}
\end{gathered}
$$



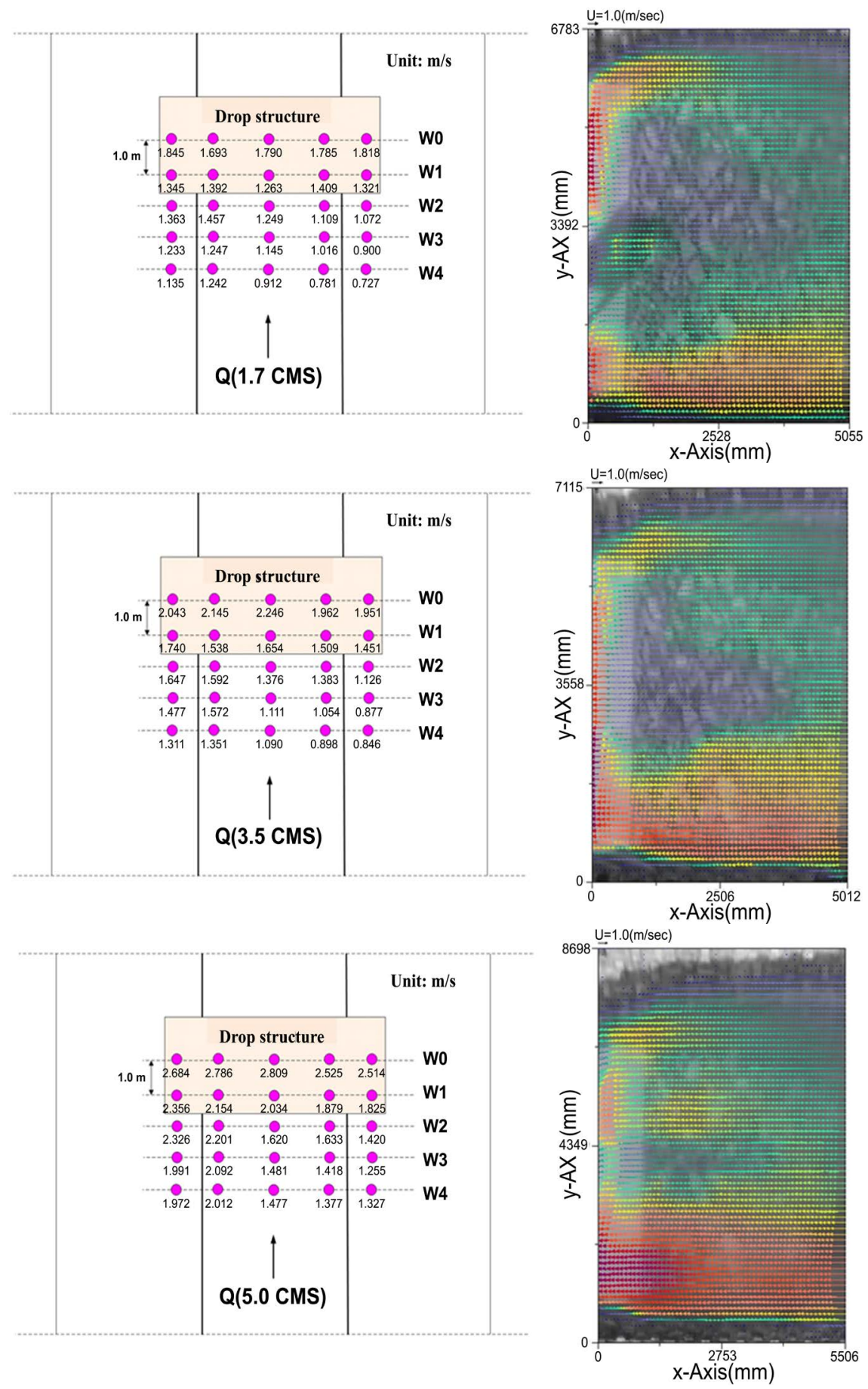

Figure 6. Velocity distribution near the drop structure.

where $L_{1}$ is the apron length, $H$ is the height of a weir from the apron (m), qis the discharge per unit $\left(\mathrm{m}^{3} / \mathrm{sec} / \mathrm{m}\right), D_{50}$ is $50 \%$ diameter of soil particle, $C$ is the Bligh's coefficient.

According to the results of comparison with the formulas presented in the River Design Criteria, when the flow amount per unit width is 0.25 , it can be observed that both the formula given by the National Construction Research In- 
stitute and Bligh's formula are distributed within the allowable threshold. Bligh's formula could be applied only to the minimum flow amount condition of 0.250 , showing that, as the flow amount increased, the results became significantly deviated from the experimental results. The formula given by the National Construction Research Institute showed a gradual difference from the experimental results from the flow amount per unit width of 0.480. As Bligh's formula for apron length does not consider the flow amount per unit width, it showed a higher difference than the formula given by the National Construction Research Institute. Table 1 compares the calculation results obtained from the conventional design criteria formulas with the experimental data from the real-scale weir and drop structure experiments. According to the Table 1, compared the experimental values of drop structure with that of weir, it could be found that the values of drop structure are changing more sharply. This seemed to be because the flow velocity at upstream of the drop structure is generally faster than that of weir, the energy of this water flow has a large effect on the downstream section. In addition, the results obtained from the Bligh's formula are constant with a given Bligh's coefficient value. This is to be because the height of a weir from the apron structure and Bligh's coefficient were only considered as design factors.

Thus, it is necessary to consider the design factors such as energy gradient and the flow amount per unit width into weir and drop structure as well as the existing design factors in designing the apron structure of a weir and drop structure.

\section{Conclusions}

This study analyzed the flow rate distribution around the structure through experiments by using real-scale weir and drop structure models, and further measured the scour length at the downstream part of the structure to compare the data with the values calculated through the existing design criteria formulas.

According to the results of comparison with the formulas presented in the River Design Criteria, when the flow amount per unit width is 0.25 , it can be observed that both the formula given by the National Construction Research Institute and Bligh's formula are distributed within the allowable threshold. Bligh's formula could be applied only to the minimum flow amount condition of 0.250 ,

Table 1. Comparison of experimental values and design formula values.

\begin{tabular}{cccccc}
\hline $\begin{array}{c}\text { Unit discharge } \\
\left(\mathrm{m}^{3} / \mathrm{s} / \mathrm{m}\right)\end{array}$ & $\begin{array}{c}\text { NCRI } \\
L_{1}(\mathrm{~m})\end{array}$ & $\begin{array}{c}\text { Bligh's formula } \\
L_{1}(\mathrm{~m})(C=4)\end{array}$ & $\begin{array}{c}\text { Bligh's formula } \\
L_{1}(\mathrm{~m})(C=6)\end{array}$ & $\begin{array}{c}\text { Experimental } \\
\text { values of weir } \\
S_{L}(\mathrm{~m})\end{array}$ & $\begin{array}{c}\text { Experimental } \\
\text { values of drop } \\
\text { structure } S_{L}(\mathrm{~m})\end{array}$ \\
\hline 0.25 & 2.51 & 2.01 & 3.01 & 1.50 & 1.23 \\
0.38 & 3.08 & 2.01 & 3.01 & 2.70 & 3.00 \\
0.48 & 3.51 & 2.01 & 3.01 & 3.60 & 3.80 \\
0.58 & 3.85 & 2.01 & 3.01 & 4.20 & 4.50 \\
0.67 & 4.13 & 2.01 & 3.01 & 4.36 & 4.70 \\
\hline
\end{tabular}


showing that, as the flow amount increased, the results became significantly deviated from the experimental results. The formula given by the National Construction Research Institute showed a gradual difference from the experimental results from the flow amount per unit width of 0.480. As Bligh's formula for apron length does not consider the flow amount per unit width, it showed a higher difference than the formula given by the National Construction Research Institute.

Future studies will improve and supplement the design standards of artificial structures such as weirs and drop structures based on experimental tests to reduce the damage from natural disasters.

\section{Acknowledgements}

This research described in this paper was financially supported by "Development of the noise reduction technology around hydraulic structure using noise cancelling system" from Korea Institute of Civil Engineering and Building Technology.

\section{Conflicts of Interest}

The authors declare no conflicts of interest regarding the publication of this paper.

\section{References}

[1] Lee, S.J. and Yoon, K.S. (2005) Safety Evaluation of Revetment around Barriers and Drop Structures. Korean Society of Civil Engineers, 887-890.

[2] Lee, S.J., Yoon, K.S. and Hwangbo, J.G. (2006) Design of Revetment around Barriers and Drop Structures. Korean Society of Civil Engineers, 331-334.

[3] Gaudio, R., Marion, A. and Bovolin, V. (2000) Morphological Effects of Bed Sills in Degrading Rivers. Journal of Hydraulic Research, 38, 89-96. https://doi.org/10.1080/00221680009498344

[4] Lenzi, M.A., Marion, A., Comiti, F. and Gaudio, R. (2002) Local Scouring in Low and High Gradient Streams at Bed Sills. Journal of Hydraulic Research, 40, 731-739. https://doi.org/10.1080/00221680209499919

[5] Lee, S.O., Yoon, S.E. and Song, J.W. (2011) Temporal Variation of Local Scour Depth in the Downstream of Weir with Shapes. Journal of Korean Society of Civil Engineers, 31, 353-360.

[6] Lashkarara, B., Ghotbi, S.M.H. and Armaghani, A. (2012) Managing Local Scour Downstream of Cross-River Structures Case Study: Balaroud Inverted Siphon. World Applied Sciences Journal, 20, 570-576.

[7] Helal, E.Y. (2014) Minimizing Scour Downstream of Hydraulic Structures Using Single Line of Floor Water Jets. Ain Shams Engineering Journal, 05, 17-28. https://doi.org/10.1016/j.asej.2013.06.001

[8] Ahmed A.A.M. (2015) Physical Model Study for Mitigating Local Scour Downstream of Clear Over-Fall Weirs. Ain Shams Engineering Journal, 06, 1143-1150. https://doi.org/10.1016/j.asej.2015.03.013

[9] KWRA (2009) Rivers Design Criteria \& Commentary. KWRA, Korea. 